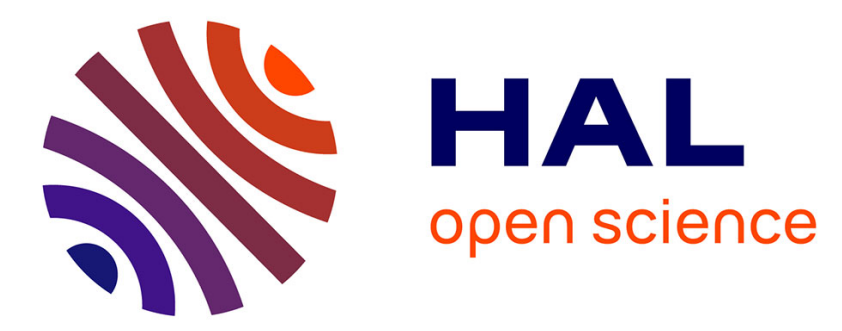

\title{
Mesoscale cloud pattern classification over ocean with a neural network using a new index of cloud variability
}

\author{
D. Lafont, O. Jourdan, B. Guillemet
}

\section{To cite this version:}

D. Lafont, O. Jourdan, B. Guillemet. Mesoscale cloud pattern classification over ocean with a neural network using a new index of cloud variability. International Journal of Remote Sensing, 2007, 27 (16), pp.3533-3552. 10.1080/01431160500192512 . hal-01982556

\section{HAL Id: hal-01982556 https://hal.science/hal-01982556}

Submitted on 22 Jan 2021

HAL is a multi-disciplinary open access archive for the deposit and dissemination of scientific research documents, whether they are published or not. The documents may come from teaching and research institutions in France or abroad, or from public or private research centers.
L'archive ouverte pluridisciplinaire HAL, est destinée au dépôt et à la diffusion de documents scientifiques de niveau recherche, publiés ou non, émanant des établissements d'enseignement et de recherche français ou étrangers, des laboratoires publics ou privés. 


\title{
Mesoscale Cloud Patterns Classification Over Ocean With a Neural Network Using a New Index of Cloud Variability
}

\author{
Damien Lafont \\ Laboratoire de Météorologie Physique, CNRS, Université Blaise Pascal \\ Observatoire de Physique du Globe de Clermont-Ferrand, France \\ Olivier Jourdan \\ Institute of Environmental Physics \\ University of Bremen, Bremen, Germany \\ and \\ Bernard Guillemet \\ Laboratoire de Météorologie Physique, CNRS, Université Blaise Pascal \\ Observatoire de Physique du Globe de Clermont-Ferrand, France \\ Revised manuscript \\ Submitted to International Journal of Remote Sensing, March 2005
}

Corresponding Author:

\section{Damien Lafont}

Laboratoire de Météorologie Physique

CNRS / Université Blaise Pascal

24, avenue des Landais

63177 Aubière cedex

FRANCE

E-mail: D.Lafont@opgc.univ-bpclermont.fr

Phone: (33) 473405274 
Fax: (33) 473405136 


\begin{abstract}
The purpose of this study is to determine the feasibility of a mesoscale $(<300 \mathrm{~km})$ cloud classification using infrared radiance data of satellite-borne instruments. We present a new method involving an index called the diversity index (DI), derived from a parameter commonly used to describe ecosystem variability. In this respect, we consider several classes of value ranges of standard deviation of the brightness temperature at $11 \mu \mathrm{m}\left(\sigma_{\mathrm{B} T}\right)$. In order to calculate $D I$ for $128 \times 128 \mathrm{~km}^{2}$ grids, subframes of $8 \mathrm{~km} \times 8 \mathrm{~km}$ are superimposed to the satellite image, and then $\sigma_{\mathrm{B} T}$ is calculated for all 256 subframes and assigned to one of the classes. Each observed cloud pattern is associated with an index characterized by the frequency of $\sigma_{B T}$-classes within the scene, representative of a cloud type. Classification of different clouds is obtained from Advanced Very High Resolution Radiometer (AVHRR)NOAA 16 data at $1 \mathrm{~km}$ resolution. Stratus, stratocumulus and cumulus are specifically recognized by this window analysis using a DI threshold. Then, a six-class scheme is presented, with the standard deviation of the infrared brightness temperature of the entire cloud scene $\left(\sigma_{c}\right)$ and $D I$ as inputs of a neural network algorithm. This neural network classifier achieves an overall accuracy of $77.5 \%$ for a six-class scheme, and $79.4 \%$ for threeclass, as verified against the analyses of nephanalists. As an application of the proposed methodology, regional cloud variability over Pacific is examined using cloud patterns derived from the Moderate Imaging Spectroradiometer System (MODIS) carried aboard Earth Observing System (EOS) Terra polar orbiter platform, for February 2003 and 2004. The comparison shows regional change in monthly mean cloud types, associated with $2003 \mathrm{El}$ Niño and 2004 neutral events. A significant increase in the occurrence of convective clouds $(+15 \%)$ and a decrease in stratiform clouds $(-10 \%)$ are observed between the two months.
\end{abstract}




\section{Introduction}

Satellite remote sensing is the most effective method for investigating spatial and temporal variations of clouds properties. In particular, information related to cloud type is essential when dealing with climatological problems (Schiffer and Rossow 1983, Stowe et al. 1988). Indeed, cloud arrangement is of great importance for practical applications, since different cloud patterns and types can lead to very different values of radiative fluxes. Welch and Wielicki (1984) have showed that gaps between clouds modify the reflectivity properties, and that different cloud patterns, with the same fractional coverage and water content, can produce very different radiative fluxes. Thus, accurate observations of cloud cover in space are important to determine quantitatively the magnitude of clouds radiative forcing (Inoue and Ackerman 2002). Clearly, cloud inhomogeneities and cloud spatial patterns are important variables (Sengupta et al. 1990), and the estimation of the spatial inhomogeneity, and more specifically, the degree to which the earth's cloud cover is structured and organized remains an important issue in cloud study.

Satellite images (Scorer 1986) highlight that cloud fields are spatially organized in recognizable mesoscale morphologies (Garand 1988, Carvalho and Dias 1998), which may reveal specific information on the physical state of the atmosphere. The clouds in a satellite picture are either quite randomly distributed or organized into mesoscale cloud formation with some regularity of pattern (Plank 1969, Kuo et al. 1993). Such patterns are important both for identifying certain cloud types and for explaining the physical processes that produce them.

The structures in cloud fields (layers, cloud free areas inside ...etc) result from interactions between the cloud itself and the ambient atmosphere. Usually, traditional statistical measures, such as fractional coverage, size distributions of cloud elements, and mutual distances between them are used to describe these cloud fields, in particular to model their radiative properties. 
Practical considerations limit representation of this cloud variability in global climate and weather forecast models to spatial scales larger than about $100-300 \mathrm{~km}$. Since the relationship between cloud properties and radiative fluxes is not linear, the presence of cloud variability at smaller scales (we call scales $<300 \mathrm{~km}$, mesoscale) creates biases in the modelled radiative fluxes. To correct these inhomogeneity effects, climate models use the property of fractional coverage, but it is essential not only to determine cloud cover, but also to distinguish cloud type (low, middle and high) and cloud subspecies (stratocumulus, stratus). Therefore the developpement of more methods to consider additional large-scale cloud parameters from satellites is important to improve our comprehension of light interactions in the atmosphere system through radiative processes.

Usually, the different cloud types were identified routinely in terms of the forms of individual clouds or cloud elements as seen from fixed positions on the ground, prior to the advent of weather satellites. A useful reference classification which has been developed in detail is laid out in the International Cloud Atlas (W.M.O 1987). From this conventional viewpoint, clouds are classified best on the joint bases of their altitudes and general appearances. Characteristics of form (i.e., cumuliform or fibrous), brightness pattern (i.e., bands, eddies, etc.), size and wavelength, when applicable, are used in classifying clouds.

Taking advantage of multispectral satellite radiometers, standard cloud algorithms rely on multispectral signatures to identify high, medium and low clouds. To date, most of cloud classification schemes apply a bispectral approach with a combination of infrared (IR) and visible channels (VIS) (Tsonis 1984, Inoue 1987, Rossow and Shiffer 1991). Other methods use cloud liquid water path derived from microwave channels (Alishouse et al. 1990, Liu and Curry 1992, Liu and Curry 1993, Greenwald et al. 1997), or combined infrared and microwave satellite data (Liu et al. 1993, Masunaga et al. 2002). In these classical methods the main cloud types are separated according to height (by reference to IR values) and thickness (by reference to the VIS values). However, most of these schemes have difficulties 
in distinguishing particular subspecies cloud types often classifying cloud merely as high, medium or low. A mixture of feature types has been shown on other examinations (Garand 1988, Chen et al. 1989, Key 1990, Lee et al. 1990, Gu and Duncan, 1991, Arai, 1993) to provide higher classification accuracies than the use of a single or a bispectral type. A review of the available schemes is provided by Pankiewicz (1995). Although textural features (Ebert 1987, Welch et al. 1988, Kuo et al. 1989, Bankert 1994, Christodoulou et al. 2003) can be used to classify cloud subclasses, a drawback of this pixel-by-pixel method, is that it cannot detect mesoscale cloud pattern (Garand 1988). In fact, although useful at a local scale, many of these procedures are less efficient in regional applications.

While the number of approaches to cloud classification continually increases, there have been few attempts to perform mesoscale cloud classification (Garand and Weinman 1986, Garand 1988, Browning 1989, Carvalho et Dias 1998). However in the visual observations of satellite images, clear differences usually appear in mesoscale spatial distribution of the main cloud types, specially between scattered cumulus, composed of a large number of clouds or cloud groups and more homogeneous stratiform clouds (Cho 1978, Hozumi et al. 1982). Both theoretical and observational evidences have been presented to support cloud field clustering in some cases and cloud field regularity in other cases (Parker et al. 1986, Weger et al. 1992, Zhu et al. 1992, Weger et al. 1993). Synoptic analyses have been successfully developed (Lau and Crane 1995), but these are most useful when describing weather types or air masses within an area up to few thousand kilometres squared. The fact that organizations within the earth's atmosphere are not infinite in form despite their rich variety in detail, but are composed instead of small group of basic shapes which may recur across a wide range of scales raises the question: "Can we translate these observations in a statistical way?”

For mesocale studies the scale of analysis should be compatible with the structure of cloud patterns. In their work on image modelling of cloud field, Garand and Weinman (1986) 
found that this scale should be between 100 and $250 \mathrm{~km}$. Such scale is large enough for mesoscale pattern to be recognizable, and small enough to insure a high probability of homogeneity of the cloud type. From these considerations, the scale of analysis employed in this study is $128 \mathrm{~km}$, a scale similar to that of climate models.

The strategy of this study is to provide a simple index for regional cloud studies depending on a limited number of parameters characterizing the cloud field. To this aim, we use an analogy with a parameter used in ecology and measuring diversity. Indeed, different statistical methods have been introduced to characterize the diversity of ecosystems. One of these methods is the so-called Shannon-Weaver diversity index (Magurran 1988), which is based on the frequency of occurrence of species in a given ecosystem.

This new methodology, classifying cloud strictly on the basis of spatial infrared brightness patterns derived from a single channel is a conceptual reversal of schemes that use a combination of different channels or sensors. Indeed, only few investigations are concerned with the potentiality of a single-channel spatial classification scheme. Only Welch et al. (1988) and Lee et al. (1990) have presented a classification based on textural features alone, derived from a single near-infrared channel and visible channel respectively.

The objective of the present study is to investigate the application of a combined DI-neural network approach to the cloud classification at mesoscale. As will be shown later in the paper, the neural network classifier only using a single-channel infrared imagery will allow an accurate characterization of cloud pattern in a simple form, without the explicit cloud top temperature or cloud top pressure information.

The paper is organized as follows. Section 2 describes the data. Section 3 introduces the concept of the diversity index. Section 4 presents the analysis of low-level clouds by means of the diversity index and describes the neural network approach applied to the cloud classification. As an application of this method, we compare in section 4c observed cloud 
patterns associated with two climatic events. Finally, some conclusions and further remarks are given in section 5 .

2. Data

For this work we have used a database of cloud patterns representative of different cloud types at $1 \mathrm{~km}$ resolution obtained from AVHRR-NOAA 16 between June 2003 and February 2004 over ocean. Six different types of cloud patterns are used: stratus (ST), stratocumulus (SC), cumulus (CU), altocumulus (AC), cumulonimbus (CB) and cirrus (CI). The cloud fields are obtained from random grids of $128 \times 128$ pixels within AVHRR-channel 4 scenes, calibrated to brightness temperature, giving 40 test grids for a given cloud type. The satellite images were labelled into six cloud types by expert analysis (i.e. cloud mask based on IR threshold, completed by visual analysis) from the CMS (Centre de Météorologie Spatiale). Figure 1 provides examples of infrared images for six different cloud types. Stratus field (figure 1a) is recognizable by its smooth texture and is arranged in a uniform, featureless layer of cloud. Stratocumulus (figure 1b) are characterized by a layer of patches composed of masses arranged in groups, lines or waves and having a soft, grey appearance. Cumulus (figure 1c) are detached, dense, clouds typically formed by clouds of width limited to few kilometres and often with streets and rolls, both obviously directional patterns. For convective regions, one would expect either highly inhomogeneous cloud situations with a large part of clear sky, or overcast scenes (figure 1e). Even worse still, from the point of view of a 1-km resolution radiometer, clouds are frequently broken or discontinuous, but we will not take into account this subpixel heterogeneity. In section 4 we shall try to identify clouds comparing $D I$ with well identified cloud types obtained from the CMS experts. 


\section{Method}

\subsection{Diversity Index}

The intrinsic variability of cloud's properties is used to extract structural information on clouds and thus to infer subgrid parametrization. This additional information can consist either in spectral or in spatial features. Usually, statistical tools are used in order to quantify the heterogeneity of clouds: structure functions (Davies et al. 1997), standard deviation (Sèze and Desbois 1987, Dioszeghy and Fejes 1995), variance (Miletta and Katsaros 1995) or other more complex parameters (Roberti et al. 1994, Mc Collum and Krajewski 1998). However for our scale of study, these parameters do not appear adequate to describe the complexity of cloud patterns. Indeed, in a mesoscale study more information is needed than the one available in radiance measurements from each channel of an isolated pixel. The required additional information could be obtained by textural features (spatial distribution characteristics of gray levels), but the information on cloud form is lost in the averaging process over large area.

A different way to characterize variability or diversity of a sample is to quantify the information within the framework of the information theory. Indeed, quantity of the form:

$$
H=-\sum_{i}\left(p_{i} \cdot \log _{2}\left(p_{i}\right)\right)
$$

plays a central role in the theory of information as a measurement of information and is recognized as the entropy as defined in certain formulations of statistical mechanics where $p_{i}$ is the probability of a system being in a state i (Shannon 1948, Weaver and Shannon 1949). The choice of a logarithmic base corresponds to the choice of a unit for measuring the information. If the base 2 is used, the resulting units are called bits. The diversity index is 
inferred from the method of calculation of the Shannon-Weaver diversity index (i.e. a parameter based on $\mathrm{H}$ and devoted to the measurement of the diversity of ecosystems) (Magurran 1988). For a given sample, $\mathrm{N}$ elements and $\mathrm{S}$ classes are considered. As it is only a sample, the probabilities are replaced by the observed frequency:

$$
p_{i}=f_{i}=\frac{N_{i}}{N}
$$

where $\mathrm{N}_{\mathrm{i}}$ is the size of the ith class in the sample and $\mathrm{N}$ the total number of elements in the sample $\left(\Sigma \mathrm{N}_{\mathrm{i}}=\mathrm{N}\right)$. The Shannon-Weaver diversity index corresponds to the entropy, $\mathrm{H}^{\prime}$, calculated in these conditions:

$$
H^{\prime}=-\sum_{i}^{S}\left(f_{i} \cdot \log _{2}\left(f_{i}\right)\right)
$$

In order to adapt the Shannon-Weaver diversity index to cloud patterns analysis, we first need to define a suitable parameter and the classes of the system.

A grid was superimposed on the satellite image. Selected image of $128 \mathrm{~km} \times 128 \mathrm{~km}$ is subdivided into square tiles of $8 \mathrm{~km} \times 8 \mathrm{~km}$, for which the clouds are frequently broken or discontinuous, thus giving 256 subframes for a given cloud pattern (figure 2). Therefore, each subframe encompasses 64 AVHRR pixels. Such a scene-frame-subframe decomposition has already been used by Coakley and Baldwin (1984) and Chang and Coakley (1993) in cloud cover analyses at two different scales.

Here, using (3), with $f_{i}$ the frequency of the ith class of the standard deviation of brightness temperature, we defined 10 classes of $\sigma_{\mathrm{B} T}(\mathrm{~S}=10)$. From these $10 \sigma_{\mathrm{B} T}$-class, one can calculate for a given grid, a combination that only depends on the standard deviation of the infrared brightness temperature, the diversity index: 


$$
D I=-\sum_{i}^{S=10}\left(f_{i} \cdot \log _{2}\left(f_{i}\right)\right)
$$

with $\mathrm{f}_{\mathrm{i}}=\mathrm{N}_{\mathrm{i}} / \mathrm{N}$ and $\mathrm{N}$ the total number of $8 \mathrm{~km} \times 8 \mathrm{~km}$ subframes in the grid area, and $\mathrm{N}_{\mathrm{i}}$ the number of members of the ith class $\left(\mathrm{f}_{\mathrm{i}}=\mathrm{N}_{\mathrm{i}} / 256\right)$. To check the dependence of $D I$ on the number of classes, we have varied this parameter from 8 to 12 . A 10-class scheme seems to be appropriate for a simple and complete description of the cloud patterns. The diversity index generally met in all samples, ranges from 1 ( 0.5 is a very low value) to around 3 and the maximum $D I$ is realized by the equal frequency of classes, and are equal to the logarithm in basis 2 of the number of classes, here $\log _{2}(10)$.

Next, this method works following two steps: the first step calculates the local standard deviation for each subframes then the second one calculates the diversity index assigning this $\sigma_{B T}$ to one of 10 defined classes.

This index differs from the recognized texture measurement of entropy used by other investigators who apply texture methods because it uses a fixed grid and is directly defined for the entire cloud scene without averaging process.

\subsection{Neural network}

Neural networks have been applied to a variety of geophysical and remote sensing studies (Krasnopolsky and Shiller, 2003; Krasnopolsky and Chevallier, 2003) to solve inverse problems either in modelling studies (Tsintikidis et al, 1997, Faure et al. 2001), or in practical cloud classification study (Jourdan et al. 2003). Previous results of cloud observation (Aviolat et al, 1998), cloud segmentation (Peak and Tag 1994, Yahnn and Simpson 1995) and cloud classification (Key et al. 1989, Lee et al. 1990, Welch et al. 1992, Bankert 1994, Bankert and Aha 1996, Miller and Emery 1997, Tian et al. 1999) also demonstrate the potential of neural network algorithm in cloud study. Neural network are composed of many nonlinear computational elements (called neurons) operating in parallel and linked to each other through connections. This structure makes neural networks inherently suitable for solving nonlinear problems. The determination of the adapted architecture is done in an empirical way, testing for various architectures, but there appears to be no simple way for determining the exact number of nodes required for these layers to function properly (Lee et al. 1990). Various 
combinations are investigated with respect to accuracy of the cloud classification. There is no simple method of determining the minimum number of hidden nodes for a given problem. We find that two hidden layers consisting of 5 and 6 components (neurones) respectively are sufficient for the present problem. It seems that fewer nodes do not extract enough information to separate the classes adequately and that too many nodes slow-down the learning phase without improving accuracy. For the supervised learning, initiated by selecting a representative set of pattern examples, the neural network is trained using the LevenbergMarquardt algorithm for the back-propagation with MacKay's Bayesian regularization (MacKay 1992). The MATLAB neural network toolbox was used.

The input data are DI and the standard deviation of the infrared brightness temperature at $11 \mu \mathrm{m}$ for the entire scene, $\sigma_{c}$, obtained from AVHRR channel 4. The outputs are the six cloud types namely, ST, SC, AC, CU, CB and CI. Training with the labelled cloud patterns allows varying the input and output parameters freely and ensures the consistency of the training data. We have to test the generalization ability of the NN trained above to evaluate its performance in retrieving the different cloud types. Accordingly, a test data is prepared by sampling randomly patterns from our database. Thus, the whole database, consisting of patterns $\left(128 \times 128 \mathrm{~km}^{2}\right)$ chosen randomly within AVHRR cloud scenes of $500 \mathrm{~km} \times 500 \mathrm{~km}$ and $300 \mathrm{~km} \times 300 \mathrm{~km}$, is randomly divided into one learning database and one testing database. To create a relatively large dataset, 25 images are taken from 7 maritime regions of the Pacific Ocean, in the Northern Hemisphere between June 2th and 26th 2003 for the training data, and between June 2003 and February 2004 for the testing data. The training data are taken at different location and time. Therefore, the scenes are confined to neither a specific location nor time of the year. From this set of 25 infrared images, 240 cloud patterns $(128 \mathrm{~km} \times 128 \mathrm{~km})$ were extracted. One-half of the total 240 cloud scenes is used to generate the training data for the classifier. The remaining data, consisting of 120 cloud patterns from independent scenes are used as test data to determine classifier accuracy. Results of this neural network (NN) methodology, applied to mesoscale cloud classification from channel 4 emissive band from AVHRR and MODIS data are given in the following section.

\section{Results and discussion}




\subsection{Low clouds separation}

Usually, the necessary separation between clear and cloudy conditions, based upon infrared threshold, strongly depends on regional conditions, and on the sensor spatial resolution. Here, the use of $\sigma_{B T}$ provides two advantages upon current thresholding method: first, no threshold for clear sky, second: the capacity to separate low-clouds from satellite IR data should provide important information during the night when visible data are unavailable. Figure 1a-c shows examples of the variability of low-cloud cover in AVHRR infrared imagery.

If we assume the cloud level known, DI can be applied for separation into various subclasses. The three basic cloud subclasses are identified in table 1, where cumulus, stratocumulus, stratus are recognized specifically. DI values calculated for infrared images of figure 1 are 0.27 (a), 2.44 (b), 2.9 (c), 3.1 (d), 1.42 (e), 2.40 (f) respectively. DI takes high values when the AVHRR is observing broken clouds. On the basis of DI we may differentiate sheet-like clouds, cumulus-like clouds with a transitional category between the two. For cloud patterns belonging to the two stratus classes (stratus and stratocumulus), DI ranges from 0 to 2.5. For cases (b-c), corresponding to stratocumulus and cumulus, all the values of DI are greater than 1 , whereas stratus clouds (figure 1a) tend to have very small values, usually less than 1 , especially when one get closer to homogenous, overcast scene. Stratocumulus clouds have a larger value of $D I$ than stratus clouds, because fully cloudy pixels with low variability of the standard deviation are relatively more frequent for stratiform clouds. Values greater than 2.5 correspond to cumulus clouds, with the greatest values for scattered cumulus $(>3)$. Figure 1b shows that stratocumulus is composed of closely packed cells of similar brightness. Stratiform cloud fields contain clouds of approximately uniform cover, but even within these regions, significant variability can exist (Zuidema et Hartmann 1995), therefore $\sigma_{B T}$ can be used, and then $D I$. As described previously, in stratus region, $D I$ exhibits values lower than 1. The decrease of DI over this cloud field could be explained by the fact that stratiform patterns 
are homogeneous, and near overcast sky pattern exists. Whereas cumulus exhibits a high variability, stratus is quite regular and $D I$ is low. Note that, the more uniform the distribution of clouds, the lower is the variability and the lower becomes the $D I$. On the other hand, high $D I$ indicates high variability and irregular cloud patterns.

In order to test the effect of sensor spatial resolution upon $D I$, we have applied our index to degraded 2 km-resolution AVHRR data simply obtained by spatial averaging and to 4 km-resolution GOES-12 infrared radiance data (channel 4) calibrated to brightness temperature for July 7th 2003 over Indian Ocean (figure 3).

The contrast of cloud patterns that appeared between figure 1 and figure 3 is found in table 2, that shows the classification obtained for AVHHR-degraded and GOES data, where the stratus class corresponds to any stratiform class (stratus, stratocumulus), and hence the different classes tend to overlapped. This difference in cloud separation reflects changes in apparent cloud pattern, and suggests that $D I$ strongly depends on the spatial resolution. $D I$ has also been evaluated at higher scale $\left(256 \times 256 \mathrm{~km}^{2}\right)$, using GOES data, but the $4 \mathrm{~km}$ resolution renders cloud character more difficult to discern. The individual components of many types of clouds fields are also too smoothed for resolve cloud types. The spatial scale enters in very important way in the definition of the diversity index, because when the grid size changes, new causes of heterogeneity may be introduced and diversity can either increase or decrease. Finally, for a complete classification, DI alone does not allow to separate middle and highlevels cloud to low-levels, as in the case of altocumulus (figure 1d) which may be put into the same class as cumulus. However, this kind of separation can be more reliably achieved through a combined analysis of $D I$ with another parameter. In the next sections, thanks to a NN approach using $D I$ and an additional spatial feature, the cloud classification will be extended to middle and high-level clouds.

\subsection{Application to cloud classification}


The positive results in the previous section prompt a more general classification, presented in this section. In order to generalize the class separation process, a further step has to be added to the low-clouds separation of section 4a. Although largely used, the mean brightness temperature seems not adequate because at this scale, the presence of large holes within clouds makes the influence of the ground dominating. We prefer to exploit the spatial information with an additional parameter taking into account the variations of infrared radiances over the cloudy scene. Sèze and Desbois (1987) and Dioszeghy and Fejes (1995) suggested the use of the standard deviation fields of the brightness values, as a simple textural information of the cloud. Here we use the standard deviation of the infrared brightness temperature, $\sigma_{c}$, computed in the $128 \times 128$ pixel square.

Thus, only two features that characterize inhomogeneous clouds were selected: $D I$ calculated from equation (3), and $\sigma_{c}$. The steps of the classification scheme are as follows: 1 ) the cloud patterns are subdivised in $8 \times 8$ subframes, 2) for each subframe, the standard deviation of the infrared britghtness temperature $\left(\sigma_{\mathrm{B} T}\right)$ is estimated in order to calculate $\left.D I, 3\right)$ For each $128 \times 128$ subframe the standard deviation of the infrared brightness temperature $\left(\sigma_{c}\right)$ is derived, 4) $D I$ and mean $\sigma_{c}$ are combined and are used as inputs of the NN algorithm.

Results are illustrated in terms of comparisons between cloud classes from NN and from the experts' classification. Theses results produce the confusion matrix shown in table3, which shows that the algorithm works well for identifying the main cloud types. As shown in table 3, 63.8\% of the SC are classified correctly and $13.5 \%$ are misclassified as stratus. However, SC has the lowest accuracy of $63.8 \%$, with a strong tendency to be misclassified either as stratus or as CU, AC and CB. ST is classified with an accuracy of $85.5 \%$ and shows tendencies to be misclassified, both as AC and as SC. CB is classified with an accuracy of $76.3 \%$ and shows tendencies to be classified either as SC or CI. Likewise, $97.7 \%$ of cumulus are classified correctly, with none misclassified as altocumulus, cumulonimbus and cirrus and 
2.1\% misclassified as stratocumulus. Finally, 69.7\% CI are classified correctly, with 30.3\% misclassified as stratocumulus. In 5 of the 6 classes, $70 \%$ or more of the samples are correctly classified. However, there are common problems such as discriminating the CB from CI, the two cloud types are often classified as the same type. For example, in the common case of frontal cloudiness, cirrus can overlap nimbostratus leading to a misclassification of these two particular cloud types. Moreover, a significant portion of the misclassification also occurs between cirrus and SC. A possible explanation stems from the fact that high-level cirriform cloud fields often show "fuzzy" patterns and stretch along the wind field. Nevertheless, the overall classification accuracy is $77.5 \%$.

As the high variability regions of cumulus cloud fields exhibit highest accuracy values, this method may be applied to cumulus detection, which is crucial for the knowledge of cumulus cloud climatology, and to develop realistic models for cloud field structure useful in radiative transfer models (see for example Wielicki and Welch 1986, Sengupta et al. 1990).

The main advantage of the presented neural network method consists in the possibility to easily achieve different levels of classification. As an example, table 4 exhibits the result obtained using $D I$ and mean $\sigma_{m}$ as NN inputs for a three-class algorithm. Clouds are classified as high (CB, CI), middle (AC) and low (ST, SC, CU) clouds. Here, middle clouds have the lowest classification accuracy in this approach (64.8\%). This poor performance is partly attributed to the lack of samples (middle clouds count only one class). Low clouds are retrieved with an accuracy of $87.8 \%$, and high at $85.5 \%$. The misclassification of high clouds as low one is due in part to overcast CB characterized by homogeneous distribution associated with DI values close to those of ST. Overall accuracy for the classifier is $79.4 \%$.

As there is no mesoscale classification using neural network algorithms, the accuracy which can be attained at this scale remain poorly documented and we can only compare our results with those at pixel scale. For example, Bankert and Aha (1996) found accuracies of 
92.0\%, 83.0\% and $90.9 \%$ for low, middle and high clouds respectively, for a five-class NN classifier, with 2 channels (IR, VIS) and 13 spectral and textural features.

In any case, our method provides an efficient way to classify cloud types that can be used in climatological or meteorological applications. In the following section we shall report on our attempts to classify the main cloud patterns that occur during two climatic conditions over ocean.

\subsection{Climatological application}

Satellite identification of clouds and cloud organizations remain the main key to many uses of satellite images in meteorology and climatology. Mesoscale approaches can generally be subdivided by the type of climatological phenomena evaluated, as well as the spatial applicability of each approach (Browning 1989). Here, in such climatological perspective, DI is applied to the climatology of clouds occurrence during two climatic conditions associated with the El Niño Southern Oscillation (ENSO). El Niño occurs when sea-surfacetemperatures in the equatorial Pacific Ocean remain significantly above average for three or more months, which can change atmospheric and weather patterns around the world (Neelin et al. 1998). In the beginning of 2003, El Niño has reached its mature stage (Vecchi and Harrisson 2003), whereas in February 2004 the conditions in the equatorial Pacific are near average, or what meteorologists call, ENSO-neutral. During the ENSO-neutral periods other climate patterns, such as the Pacific North America pattern, become dominant players that could affect cold-season temperature and precipitation patterns over North America, and there is a higher degree of uncertainty in what we can expect in regards to temperature and precipitation patterns. Our ability to predict El Niño is dependent of our global understanding of the air-sea interaction over the Pacific area, and therefore on our understanding of clouds dynamics and occurrences. 
For this climatological application, the same procedure as in section $4 \mathrm{~b}$ is applied but this time with satellite images collected over the Pacific ocean $\left(1^{\circ} \mathrm{N}-1^{\circ} \mathrm{S}, 103^{\circ} \mathrm{W}-99^{\circ} \mathrm{W}\right)$ from the Moderate Resolution Imaging Spectroradiometer (MODIS) aboard Terra platform. MODIS measures radiation in 36 narrow spectral bands situated between 0.4 and $14.4 \mu \mathrm{m}$, in sun-synchronous orbits. The $1 \mathrm{~B}$ data channel 31, at $1 \mathrm{~km}$ resolution is used in this application.

Each image is divided into eight $128 \times 128$ pixel subregions for classification. A further subdivision of each of these regions into sets of $8 \times 8$ pixel smaller subregions is made for the computation of the diversity index. Each of the grids is identified and labelled as belonging to one of six classes. For the two months, daily index of the cloud type are built from about 500 scenes categorized into 6 classes. We focus on cloudy patterns in selecting only grid with cloud fraction higher than $5 \%$.

Regional diurnal cloud variability is examined using cloud patterns derived from February 2003 and February 2004 MODIS $11 \mu \mathrm{m}$ infrared data. Figure 5 describes the zone of study (512 km $\times 256 \mathrm{~km})$. An example image with MODIS channel 31 sample regions $(128 \times 128)$ marked in boxes is presented in figure 5 . Figure 6 depicts representative cloud patterns and their associated DI. We can observe complex patterns in the convective cloud fields, whereas a continuous gradient is more apparent for ST. In particular, as for AVHRR data, low values are associated with stratiform clouds, whereas higher DI is found for convective clouds at various stages of development. DI ranges between 0.71 (ST) and 3.07 (CU) over the wide range of observed conditions. For (c) and (d) DI is near 2.5 and no rough differences are found among CU and AC. Convective clouds have an horizontal dimension of few kilometres, which is small compared to our scale of study. Only a part of the grid is therefore usually covered by clouds (cf. figure 6a). Stratus (figure 6a) are predominantly pale grey and contrast markedly with the very bright appearances of cumulonimbus (figure $6 \mathrm{~d}$ and $6 e)$. 
Frequency of occurrence of each cloud type has been established to interpret the prevailing sky conditions. Table 5 provides the cloud type occurrences for February 2003 and 2004 in six classes and clear sky, in a $4^{\circ} \times 2^{\circ}$ area, yet permits rapid comparison of monthly cloud pattern across a relative large region.

The low occurrence of CU (7.5\%) in 2003 indicates a low variability of the cloud sequences containing sparse patterns like in figure 6b. Completely overcast conditions (ST) are more likely to be found during this period, which shows a quite uniform repartition between the different cloudy patterns. On the other hand, February 2004 exhibits more complex patterns, through the presence of CB. A closer look reveals that February 2004 was characterized by several convective events that lasted 8 days between the tenth and seventeenth. As a result, mesoscale convective patterns (CB) are more frequent during this period. The comparative analysis between the two months reported differences among cloud patterns within the same region. First, the largest cloud variations occur for CB with an increase of $10 \%$ between the two events. Further comparisons show that in 2004 CB generally appear two times more than CI. February 2003 show an opposite occurrence. A remarkable result is that ST occurred less than $5 \%$ of the time as opposed to $22.5 \%$ for convective clouds. February 2004 is characterized by a value of ST 10\% lower than in February 2003. As these two types of clouds have an opposite radiative role, one can expected very different radiative effects. Not all patterns demonstrate this magnitude of temporal variability (CB and ST) for example CU and SC are quite constant. Finally, high clouds (CI), and midlevel clouds occur most frequently during the 2003 ENSO-related event. On the average, clear sky varied about $10 \%$ in this area too. The increase of CB during the neutral period could be explained by the presence of highly unstable air. Most complex structures can be observed in such patterns, develop in response to a wide variety of atmospheric and surface factors, including the strength of horizontal air motion, the intensity of convection and its organization, vertical and horizontal variations in wind speeds. 
Stratus (ST) tend to occur extensively or not at all; extensive stratus occurred on 5, 6 and 16 February but no such cases happened in February 2004, resulting in a marked discrepancy for that class. The patterns related to convection (CB and CU) account for 30\% of the samples in Feb 2004, whereas they account for only 15\% in 2003.

Throughout these spatial and temporal changes, the influence of large scale climatic regime on regional cloud pattern is clear. Results from this analysis has revealed dominant patterns which tended to be replaced by other patterns which were in minority in the previous conditions. The amount of cloud patterns in the different classes gives insight on the variation in atmospheric conditions which could be associated with changes in oceanic conditions such as increase or decrease in SST. Indeed, most tropical precipitation can be characterized by convective and stratifom systems (Houze 1993). Convective systems are associated with strong vertical velocity fields, small area coverage cells, and high rainfall intensities. Stratiform systems are characterized by widespread slow ascent velocity fields, associated with low rainfall intensities. At low latitudes convective systems heat the atmosphere due to condensation of water vapor, while stratiform system cool the atmosphere due to evaporation of raindrops. As a result of the above differences, each system impacts on the ocean mixed layer characteristics and the sea surface surface temperature differently (Webster and Lukas 1992). However, a detail analysis of ocean and climate dynamic over this region is beyond the scope of this cloud study.

Regions such as the tropics will present a great challenge because of a frequent overlapping of various clouds types. Due to the above difference the two systems have different latent heating profiles which impact the earth's climate differently. Therefore, the presence of CB, as opposed to low-stratiform clouds may have a larger impact upon cloud albedo. The proposed method will help to quantify the complexities of cloud patterns, important information especially for modellers, who have to parameterize subgrid effects for a better knowledge of 
radiative effects of inhomogeneity (Stubenrauch et al. 1999). Categorization into cloud type provides the capability of directly assessing changes in the clear-sky albedo and long-wave flux. However, there is still considerable research (field measurements and numerical simulations as well) required to fully understand the physical process which maintain cloud fields and their properties.

As a summary, despite the fact that these results are only of regional meteorological significance, the DI-NN method could have important climatological applications, such as the determination of climatic changes based on variations in cloud frequencies and character, and in precipitation characteristics (convective or stratiform).

\section{Conclusions}

In the present study, we investigated the application of a new index of cloud variability, the "diversity index", combined to a NN approach applied to the cloud classification. The characterization of cloud fields is investigated in terms of the standard deviation of infrared brightness temperature variability at two different scales (local- and mesoscale). The advantages of this new method are the small amount of computing time, and that no other data are required than one of infrared channel values, for each grid. Moreover, as this method uses only infrared radiances, it should provide equally good results for both daytime and night time observations. And, especially, as this classification does not depend on clear-sky threshold, it could be applied over land, and therefore, to cloud scenes confined to neither a specific location nor time of year. A significant finding is that relatively high accuracies are attained with this simple approach only based on two features as inputs of the neural network classifier, without information related with cloud top temperature or cloud top pressure. An analysis of AVHRR data revealed that, assuming the cloud-level known, DI can be used to separate low-level clouds into three subspecies (stratocumulus, cumulus and stratus). This window technique, allows a fairly good separation of cumulus fields from those 
covered by stratiform clouds, a difficult exercise in a pixel-by-pixel analysis. Then, a classification algorithm, implemented and tested with AVHRR data at $1 \mathrm{~km}$ resolution, is presented. In contrast to most existing cloud classification algorithms that combine visible and infrared channel, our NN method only incorporates two parameters: DI and the standard deviation of the infrared brightness temperature at $11 \mu \mathrm{m}\left(\sigma_{c}\right)$, representing texture and heterogeneity characteristics of the cloud fields respectively. This study finds that a DI-based neural network classifier only using single-channel infrared data can achieve overall cloud identification accuracy of $77.5 \%$ for six cloud types. Stratus is retrieved with an accuracy of $85.5 \%$, and stratocumulus is worst, with an accuracy of $63.8 \%$. Cirrus can be distinguished from low-layer cloudiness with an accuracy of $69.7 \%$. In a more general classification in three cloud types (low, medium and high), near $80 \%$ of the samples are accurately classified. It is significant that the present method is capable of distinguishing high clouds from low-level clouds strictly on the basis of spatial brightness patterns. However, misclassifications may occur with confusion between stratocumulus break-up regions and cumulus, between overcast scenes with cumulonimbus or stratus, or when different types of cloud are met within a grid box. Therefore, further analysis should be directed towards the detection of mixed and multilayered clouds.

As a simple illustrative application of this technique we extend our analysis to a brief climatological study from the high resolution MODIS data for February 2003 and February 2004. The main conclusion is that the method clearly enables one to distinguish different cloud pattern occurrences, and is also particularly suited for determining regional changes, such as climatic variability. In an ENSO-neutral comparison of cloud types over a limited region, we observed a significant increase in CB in 2004 associated to larger scale phenomenon. Moreover, as this infrared technique, gives reasonable results in terms of the breakdown of the cloud fields into convective and stratiform categories, it raises hope in a use in precipitation regime analysis. Throughout this regional study, the ability of the algorithm to 
characterize the main cloud types observed by satellite with a limit number of parameters is clearly demonstrated. However, this classification could be improved with other configuration of the network (see for example Bankert (1994) with a two-layer, three-network system that produces the classification from a more general to a more specific class). The classification accuracy can also be improved by increasing the data base to obtain the most representative cloud situations.

\section{Acknowledgments}

The authors thank the CMS (Centre de Météorologie Spatiale, Lannion, France)SATMOS (Service d'Archivage et de Traitement Météorologique des Observations Spatiales) for providing AVHRR satellite data. The authors also gratefully acknowledge Dr. L. Garand for his comments and help. The MODIS data used in this study were acquired as part of the NASA's Earth Science Enterprise. The algorithms were developed by the MODIS Science Teams. The data were processed by the MODIS Adaptative Processing System (MODAPS) and Goddard Distributed Active Archive Center (DAAC), and are archived and distributed by the DAAC.

\section{References}

ALISHOUSE, J. C., SNYDER, S. A., VONGSATHORN, J., FERRARO, R., 1990, Determination of oceanic total precipitable water from the SSM/I. IEEE. Transactions on Geoscience and Remote Sensing, 28, 811-816.

ARAI, K., 1993, A classification method with spatial-spectral variability. International Journal of Remote Sensing, 14, 699-709.

AVIOLAT, F., CORNU, T., CATTANI, D., 1998, Automatic cloud observation improved by an artificial neural network. Journal of Atmosphere and Oceanic Technology, 15, 114126. 
BANKERT, R. L., 1994, Cloud classification of AVHRR imagery in maritime regions using a probabilistic neural network. Journal of Applied Meteorology, 33, 909-918.

BANKERT, R. L., AND AHA, D. W., 1996, Improvement to neural network cloud classifier. Journal of Applied Meteorology, 35, 2036-2039.

BROWNING, K. A., 1989, The mesoscale data base and its use in mesoscale forecasting. Quarterly Journal of the Royal Meteorological Society, 115, 717-762.

CARVALHO, L. M. V., AND DIAS, F. S., 1998, An application of fractal box dimension to the recognition of mesoscale cloud patterns in infrared satellite images. Journal of Applied Meteorology, 37, 1265-1282.

CHANG, F. L., and COAKLEY, J. A., 1993, Estimating errors in fractional cloud cover obtained with infrared threshold methods. Journal of Geophysical Research, 98, 88258839.

CHEN, D. W., SENGUPTA, S. K., WELCH, R. M., 1989, Cloud field classification based upon high spatial resolution textural features 2. Simplified vector approaches. Journal of Geophysical Research, 94, 14749-14765.

CHO, H. R., 1978, Some statistical properties of a homogeneous and stationary shallow cumulus cloud field. Journal of the Atmospheric Sciences, 35, 125-138.

CHRISTODOUlOU, C. I., MICHAELIDES, S. C., PATTICHIS, S., 2003, Multifeatures texture analysis for the classification of clouds in satellite imagery. IEEE. Transactions on Geosciences and Remote Sensing, 41, 2662-2668.

COAKLEY, J. A., and BALDWIN, D. G., 1984, Towards the objective analysis of clouds from satellite imagery data. Journal of Climate and Applied Meteorology, 23, 10651099.

DAVIES, A., MARSHAK, A., CAHALAN, R., WISCOMBE, W., 1997, The Landsat scale break in stratocumulus as a three-dimensional radiative transfer effect: Implications for cloud remote sensing. Journal of the Atmospheric Sciences, 54, 241-260. 
DIOSZEGHY, M., and FEJES, E., 1995, Cloud classification derived from METEOSAT data involving the standard deviation fields of the brightness values. Advances in Space Research, 10, 33-36.

EBERT, E., 1987, A pattern recognition technique for distinguishing surface and cloud types in the Polar Regions. Journal of Climate and Applied Meteorology, 26, 1412-1427.

FAURE, T., ISAKA, H., GUILLEMET, B., 2001, Neural network retrieval of cloud parameters of inhomogeneous and fractional clouds: feasibility study. Remote Sensing Environment, 77, pp. 123-138.

GARAND, L., 1988, Automated recognition of oceanic cloud pattern. Part I: Methodology and application to cloud climatology. Journal of Climate, 1, 20-39.

GARAND, L., and WEINMAN, J. A., 1986, A structural-stochastic model for the analysis and synthesis of cloud images. Journal of Climate and Applied Meteorology, 25, 10521068.

GREENWALD, T. J., CHRISTOPHER, S. A., CHOU, J., 1997, Cloud liquid water path comparisons from passive microwave and solar reflectance satellite measurements: Assessments of sub-field-of-view cloud effects in microwave retrievals. Journal of Geophysical Research, 102, 19585-19596.

GU Z., and DUNCAN, C., 1991, Texture and spectral features as an aid to cloud classification. Journal of Remote Sensing, 12, 953-968.

HOZUMI, K., HARIMAYA, T., MAGONO, C., 1982, The size distribution of cumulus clouds as a function of cloud amount. Journal of the Meteorological Society of Japan, 60, 691-699.

HOUZE, R. A., 1993, Cloud Dynamics. Academic Press, 573 p. 
INOUE, T., 1987, An instantaneous delineation of convective rainfall areas using split window data of NOAA-7 AVHRR. Journal of the Meteorological Society of Japan, 65, 469-480.

INOUE, T., and ACKERMAN, S. A., 2002, Radiative effects of various cloud types as classified by the split-window technique over the eastern sub-tropical Pacific derived from collocated ERBE and AVHRR data. Journal of the Meteorological Society of Japan, 80, 1383-1394.

JOURDAN, O., OSHCHEPKOV, S., GAYET, J.-F., SHCHERBAKOV, V. AND ISAKA, H., 2003, Statistical analysis of cloud light scattering and microphysical properties obtained from airborne measurements. Journal of Geophysical Research, 108 (D5), 4155, doi:10.1029/2002JD002723.

KEY, J. R., 1990, Cloud cover analysis with Artic Advanced Very High Resolution Radiometer data. 2. Classification with spectral and textural measures. Journal of Geophysical Research, 95, 7661-7675.

KEY, J. R., and BARRY, R. G., 1989, Cloud cover analysis with artic AVHRR data. 1. Cloud detection. Journal of Geophysical Research, 94, 8521-8535.

KRASNOPOLSKY, V. M, and SHILLER, H., 2003, Some neural network applications in environmental sciences. Part I: forward and invers problems in geophysical remote measurements. Neural Networks, 16, 321-334.

KRASNOPOLSKY, V. M, and CHEVALIER, F., 2003, Some neural network applications in environmental sciences. Part II: advancing computational efficiency of environamental numerical models. Neural Networks, 16, 335-348.

KUO, K. S., WELCH, R. M., SENGUPTA, S. K., 1989, Structural and textural characteristics of cirrus clouds observed using high spatial resolution Landsat imagery. Journal of Applied Meteorology, 27, 1242-1260. 
KUO, K. S., WELCH, R. M. AND WEGER, R. C., 1993, The three-dimensional structure of cumulus clouds over the ocean. 1. Structural analysis. Journal of Geophysical Research, 98, 20685-20711.

LAU, N.-C., and CRANE, M. W., 1995, A satellite view of the synoptic-scale organization of cloud properties in midlatitude and tropical circulation systems, Monthly Weather Review, 123, 1984-2006.

LEE, J., WEGER, R. C., SENGUPTA, S. K., WELCH, R. M., 1990, A neural network approach to cloud classification. IEEE Transactions on Geoscience and Remote Sensing, 28, 846-855.

LIU, G., CURRY, J., CLAYSON, C. A., 1993, Study of tropical cyclogenesis using satellite data. Meteorol. Atmos. Phys., 56, 111-123.

LIU, G., and CURRY, J., 1992, Retrieval of precipitation from satellite microwave measurement using both emission and scattering. Journal of Geophysical Research, 97, 9959-9974.

LIU, G., and CURRY, J., 1993, Determination of characteristic features of Cloud Liquid Water from satellite microwave measurement. Journal of Geophysical Research, 98, 5069-5092.

MACKAY, D.J.C., 1992, A pratical Bayesian framework for back-propagation networks. Neural Computation, 4, 589-603.

MAGURRAN, A. E., 1988, Ecological diversity and its measurement, (London: Croom Helm).

MASUNAGA, H., NAKAJIMA, T. Y., NAKAJIMA, T., KACHI, M., SUZUKI, K., 2002, Physical properties of maritime low clouds as retrieved by combined use of Tropical Rainfall Measuring Mission (TRMM) Microwave Imager and Visible/Infrared Scanner. 2. Algorithm. Journal of Geophysical Research, 107, DOI 10.1029/2001JD001229. 
MC COLLUM, J.R., and KRAJEWSKI, W. F., 1998, Investigations of errors sources of the Global Precipitation Climatology Project emission algorithm. Journal of Geophysical Research, 103, 28711-28719.

MILLER, S. W., and EMERY, W. J., 1997, An automatic neural-network cloud classifier for use over land and ocean surface. Journal of Applied Meteorology, 36, 1346-1362.

MILETTA, J., KATSAROS, K. B., 1995, Using coincident multispectral satellite data to assess the accuracy of special sensor microwave imager liquid water path measurements. Journal of Geophysical Research, 100, 16333-16339.

NEELIN, J. D., BATTISTI, D. S., HIRST, A. C., JIN, F. F., WAKATA, Y., YAMAGATA, T. AND ZEBIAK, S. E., 1998, ENSO Theory. Journal of Geosphysical Research, 103, $14,261-14,290$.

PANKIEWICZ, G. S., 1995, Pattern recognition techniques for identification of cloud and cloud systems. Meteorol. Appl., 2, 257-271.

PARKER, L., WELCH, R. M., MUSIL, D. J., 1986, Analysis of spatial inhomogeneities in cumulus clouds using high spatial resolution Landsat data. Journal of Climate and Applied Meteorology, 25, 1301-1314.

PEAK, J.E., and TAG, P. M., 1994, Segmentation of satellite imagery using hierarchical thresholding and neural networks. Journal of Applied Meteorology, 33, 605-616.

PLANK, V. G., 1969, The size distribution of cumulus clouds in representative Florida populations. Journal of Applied Meteorology, 8, 48-67.

ROBERTI, L., HAFFERMAN, J., KUMMEROW, C., 1994, Microwave radiative transfer through horizontally inhomogeneous precipitating clouds. Journal of Geophysical Research, 99, D8, 16707-16718.

ROSSOW, W. B. AND SCHIFFER, R. A., 1991, ISCCP cloud data products. Bulletin of the American Meteorological Society, 72. 
SCHIFFER, R. A., AND ROSSOW, W. B., 1983, The International Satellite Cloud Climatology Project (ISCCP): The first project of the World Climate Research Programme. Bulletin of the American Meteorological Society, 64, 779-784.

SCORER, R.S. (1986). Cloud investigation by satellite. Ellis Horwood Limited.

SENGUPTA, S. K., WELCH, R. M., NAVAR, M. S., BERENDES, T. A., CHEN, D. W., 1990, Cumulus cloud field morphology and spatial patterns derived from high spatial resolution Landsat imagery. Journal of Applied Meteorology, 29, 1245-1267.

SÈZE, G., and DESBOIS, M., 1987, Cloud cover analysis from satellite imagery using spatial and temporal characteristics of the data. Journal of Climate and Applied Meteorology, 26, 287-307.

SHANNON, C. E., 1948, A mathematical theory of communication. The Bell System Technical Journal, 27, 379-423.

STUBENRAUCH, C. J., ROSSOW, W. B., SCOTT, N. A., CHÉDIN, A., 1999, Clouds as seen by satellite sounders (3I) and imagers (ISCCP). Part III: Spatial heterogeneity and radiative effects. Journal of Climate, 12, 3419-3442.

STOWE, L. L., WELLMEYER, C. G., ECK, T. F., YEH, H. Y. M. and the Nimbus-7 cloud data processing team, 1988, Nimbus-7 global cloud climatology. Part 1: Algorithm and validation. Journal of Climate, 1, 445-470.

TIAN, B., SHAIKH, A., AZIMI-SADJADI, M.R., VONDER HAAR, T., REINKE, D. L., 1999, A study of cloud classification with neural networks using spectral and textural features. IEEE Transactions on Neural Networks, 10, 138-151.

TSINTIKIDIS, D., HAFERMAN, J. L., ANAGNOSTOU, E. N., KRAJEWSKI, W. F., SMITH, T. F., 1997, A neural network approach to estimating rainfall from spaceborne microwave data. IEEE Transactions on Geoscience and Remote Sensing, 35, 1079-1092. TSONIS, A., 1984, On the separability of various classes from the GOES visible and infrared data. Journal of Climate and Applied Meteorology, 23, 1393-1410. 
VECCHI, G. A., and HARRISSON, D. E., 2003, On the termination of the 2002-2003 El Niño event. Geophysical Research Letter, 30, 1964, doi:10.1029/2003GL017564.

WEAVER, W., AND SHANNON, C. E., 1949, The mathematical theory of communication. Urbana, Illinois, University of Illinois Press.

WEBSTER, P.J., AND LUKAS, R., 1992, TOGA COARE: The Coupled Ocean-Atmosphere Response Experiment. Bull Amer. Meteor. Soc., 73, 1377-1416.

WEGER, R. C., LEE, J., ZHU, T., WELCH, R. M., 1992, Clustering, randomness, and regularity in cloud fields: 1. Theoretical considerations. Journal of Geophysical Research, 97, 20519-20536.

WEGER, R. C., LEE, J., AND WELCH, R. M., 1993, Clustering, randomness, and regularity in cloud fields: 3. The nature and distribution of cluster. Journal of Geophysical Research, 98, 18449-18463.

WELCH, R. M., SENGUPTA, S. K., CHEN, D. W., 1988, Cloud field classification based upon high spatial resolution textural features 1. Gray level co-occurrence matrix approach. Journal of Geophysical Research, 93, 12663-12681.

WELCH, R. M. and WIELICKI, B. A., 1984, Stratocumulus cloud field reflected fluxes: The effects of cloud shape. Journal of the Atmospheric Sciences, 41, 3085-3103.

WELCH, R. M., SENGUPTA, S. K., GOROCH, A. K., RABINDRA, P., RANGARAIJ, N., NAVAR, M. S., 1992, Polar cloud and surface classification using AVHRR imagery: An intercomparaison of methods. Journal of Applied Meteorology, 31, 405-420.

WIELICKI, B.A., and WELCH, R. M., 1986, Cumulus cloud properties derived using LANDSAT satellite data. Journal of Climate and Applied Meteorology, 25, 261-276.

W.M.O., 1987, International Cloud Atlas. World Meteorological Organization, 155 pp.

YAHNN, S.R., and SIMPSON, J. J., 1995, Application of neural networks to AVHRR cloud segmentation. IEEE Transactions on Geoscience and Remote Sensing, 33, 590-604. 
ZUIDEMA, P., and HARTMANN, D., 1995, Satellite determination of stratus cloud microphysical properties. Journal of Climate, 8, 1638-1656.

ZHU, T., LEE, J., WEGER, R. C., WELCH, R. M., 1992, Clustering, randomness, and regularity in clouds fields: 1. Cumulus cloud fields. Journal of Geophysical Research, 97, 20537-20558. 


\section{Table Captions}

Table 1. DI from AVHRR infrared measurements versus low-cloud subspecies.

Table 2. DI from infrared measurements versus low-cloud subspecies for AVHRR-2 km and GOES data.

Table 3. NN cloud classification from AVHRR data test. Overall accuracy is $77.5 \%$.

Table 4. Three classes classification. Overall accuracy is $79.4 \%$.

Table 5. Occurence of cloud types (\%) during February 2003 and February 2004. 


\section{Figure Captions}

Figure 1: Infrared (right)-visible (left) pairs of AVHRR cloud patterns $\left(128 \times 128 \mathrm{~km}^{2}\right)$ : ST (a), SC (b), CU (c), AC (d), CB (e), CI (f). The clouds in the image appear as bright shades against a dark ocean background.

Figure 2: Method of calculation of the Diversity Index.

Figure 3: Infrared (down)-visible (up) pairs of GOES-12 images $\left(128 \times 128 \mathrm{~km}^{2}\right)$, ST (a), SC (b), and CU (c).

Figure 4: Location of the region of analysis over equatorial Pacific.

Figure 5: High-resolution images from $11 \mu \mathrm{m}$ radiances for eight $128 \times 128 \mathrm{~km}^{2}$ regions over the Pacific ocean centred at $0^{\circ} \mathrm{N}-101^{\circ} \mathrm{W}$, for February $4^{\text {th }}$, 2004. The clouds in the image appear as bright shades against a dark ocean background.

Figure 6: Examples of MODIS cloud patterns classify as ST (a), CU (b), CB (c, d, e) and CI (e). DIs are $0.96,3.07,2.74,2.46,2.07$, and 2.71 respectively. 
Cloud Type Stratus Stratocumulus Cumulus

\begin{tabular}{llll}
\hline Diversity Index & $0-1$ & $1-2.5$ & $>2.5$
\end{tabular}

Table 1.

\begin{tabular}{cccc}
\hline \hline & Stratus & Stratocumulus & Cumulus \\
\hline DI from AVHRR 2 km & $1.5-2.9$ & $2.3-2.9$ & $>2.9$ \\
DI from GOES 4 km & & & $1.5-2$ \\
$\begin{array}{c}128^{\prime} 128 \mathrm{~km}^{2} \\
\text { DI from GOES 4 km }\end{array}$ & $0.5-1.9$ & $1.5-2$ & \\
$256^{\prime} 256 \mathrm{~km}^{2}$ & $0-3$ & $2.8-3$ & $2.5-3.1$ \\
\hline
\end{tabular}

Table 2.

\begin{tabular}{ccccccc}
\hline \hline & ST & SC & CU & AC & CB & CI \\
\hline ST & $\mathbf{8 5 . 5}$ & 7.4 & 0.3 & 6.8 & 0 & 0 \\
SC & 13.5 & $\mathbf{6 3 . 8}$ & 7.2 & 7.1 & 7.2 & 1.2 \\
CU & 0.2 & 2.1 & $\mathbf{9 7 . 7}$ & 0 & 0 & 0 \\
AC & 8.8 & 9.5 & 0.6 & $\mathbf{7 1 . 8}$ & 8.9 & 0.3 \\
CB & 0.3 & 11.1 & 0.8 & 0.8 & $\mathbf{7 6 . 3}$ & 10.9 \\
CI & 0.2 & 30.3 & 0 & 0 & 0 & $\mathbf{6 9 . 7}$ \\
\hline
\end{tabular}

Table 3.

\begin{tabular}{cccc}
\hline \hline & Low & Middle & High \\
\hline Low & $\mathbf{8 7 . 8}$ & 7.3 & 4.9 \\
Middle & 17.9 & $\mathbf{6 4 . 8}$ & 17.3 \\
High & 14.3 & 0.2 & $\mathbf{8 5 . 5}$ \\
\hline
\end{tabular}

Table 4.

\begin{tabular}{|c|c|c|c|c|c|c|c|}
\hline & ST & SC & $\overline{\mathrm{CU}}$ & $\mathrm{AC}$ & CB & CI & Clear \\
\hline $\begin{array}{c}\text { Feb. } 2003 \\
\text { ENSO }\end{array}$ & 13.6 & 10.9 & 7.5 & 14.3 & 7.5 & 16.4 & 29.8 \\
\hline $\begin{array}{c}\text { Feb. } 2004 \\
\text { neutral }\end{array}$ & 3.6 & 9.1 & 9.7 & 4.3 & 22.5 & 11.6 & 39.2 \\
\hline
\end{tabular}

Table 5. 

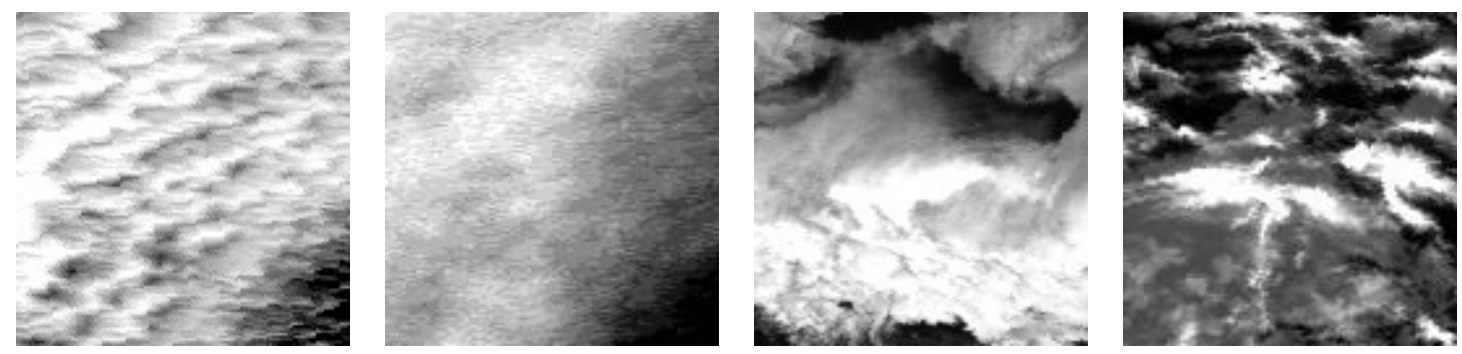

a

b
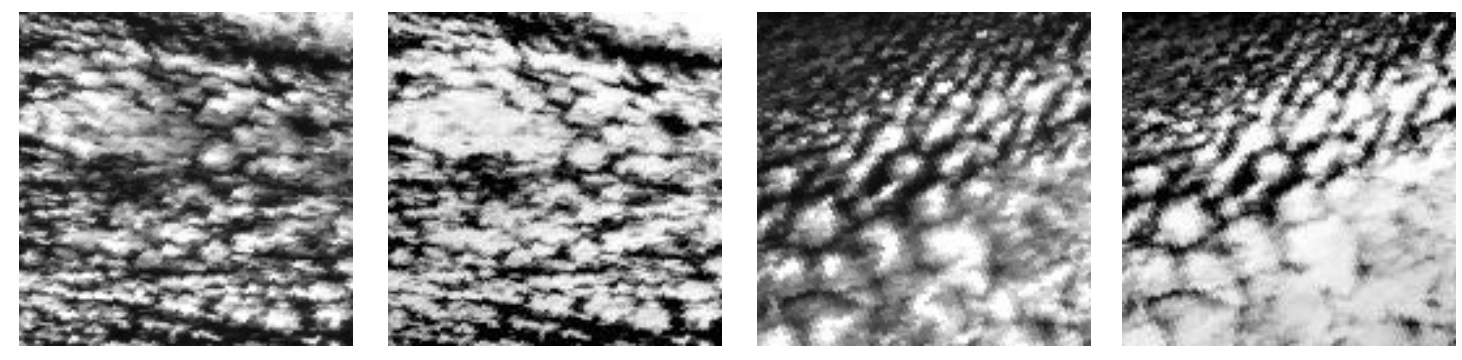

C
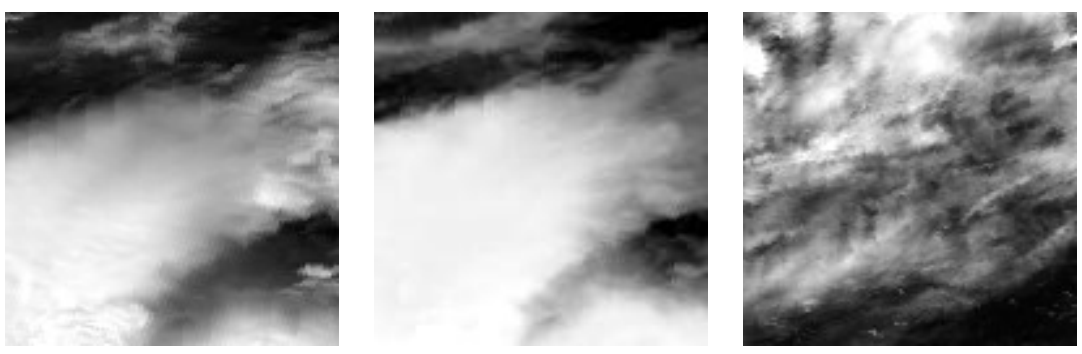

d

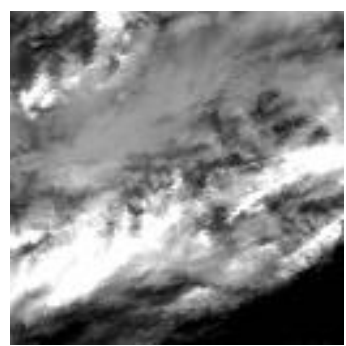

e

f

Figure 1 


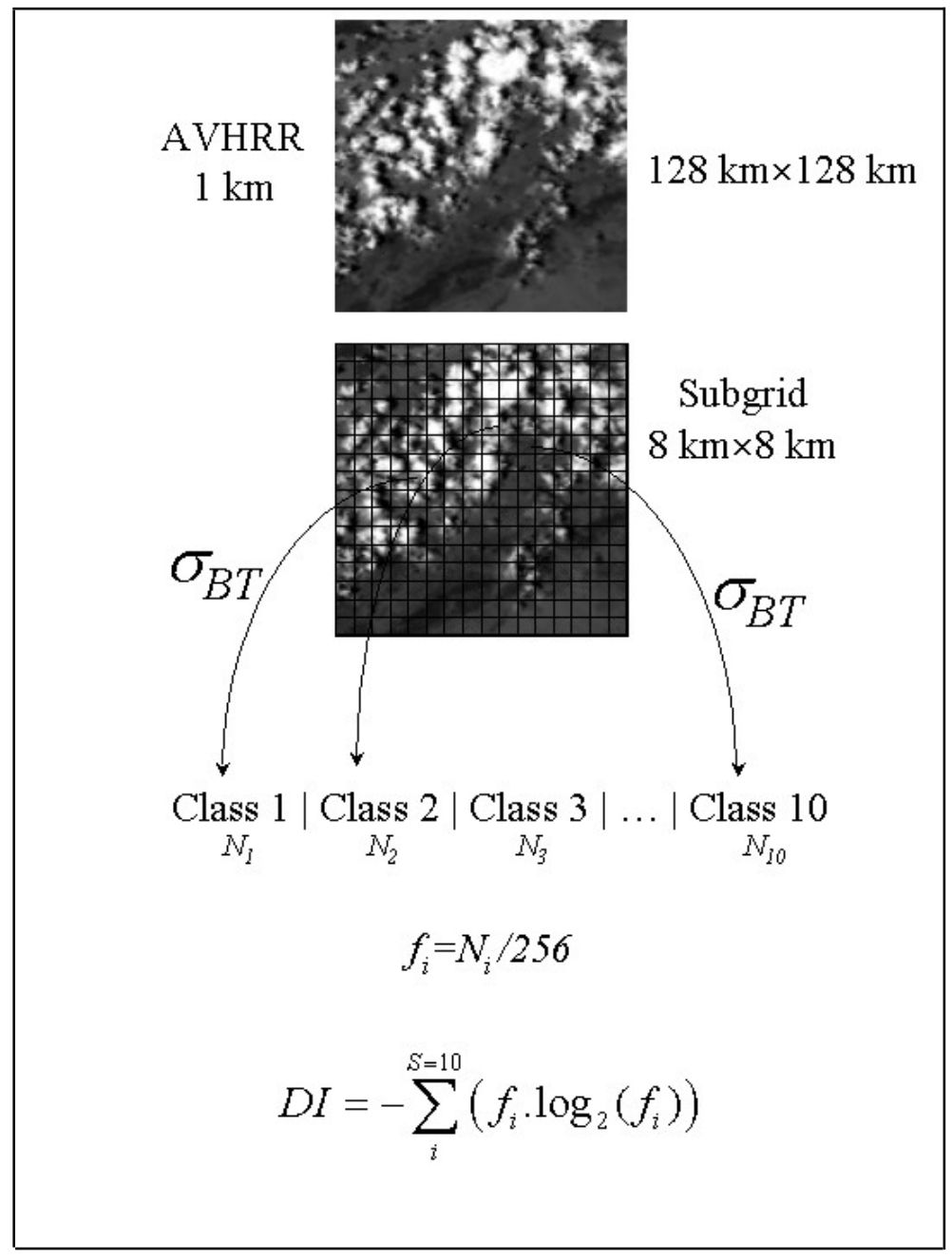

Figure 2 


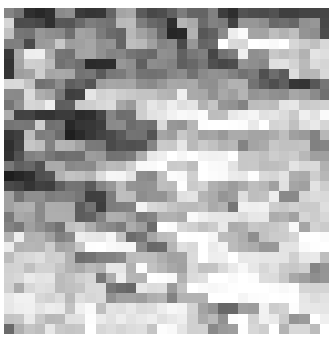

a

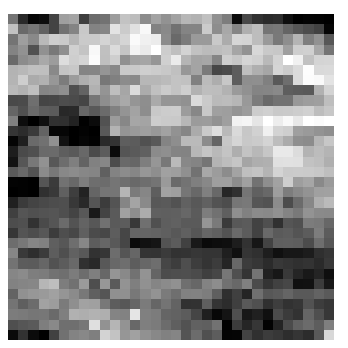

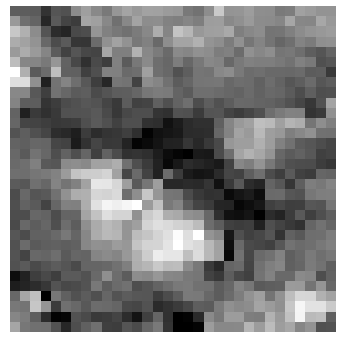

b

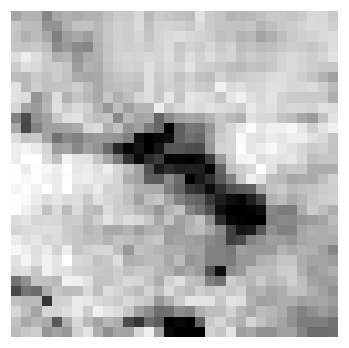

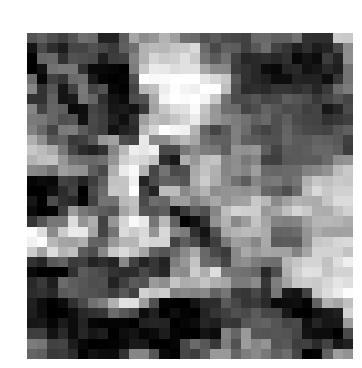

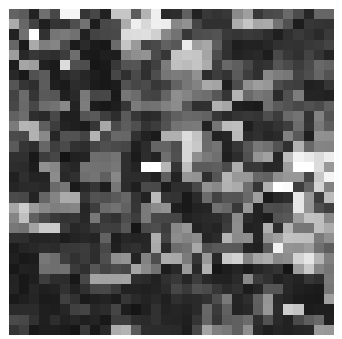

C

Figure 3 


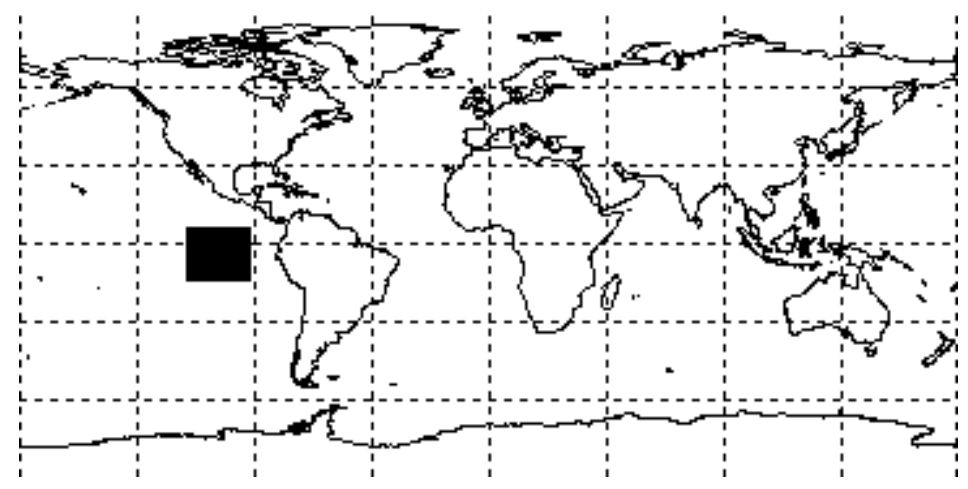

Figure 4

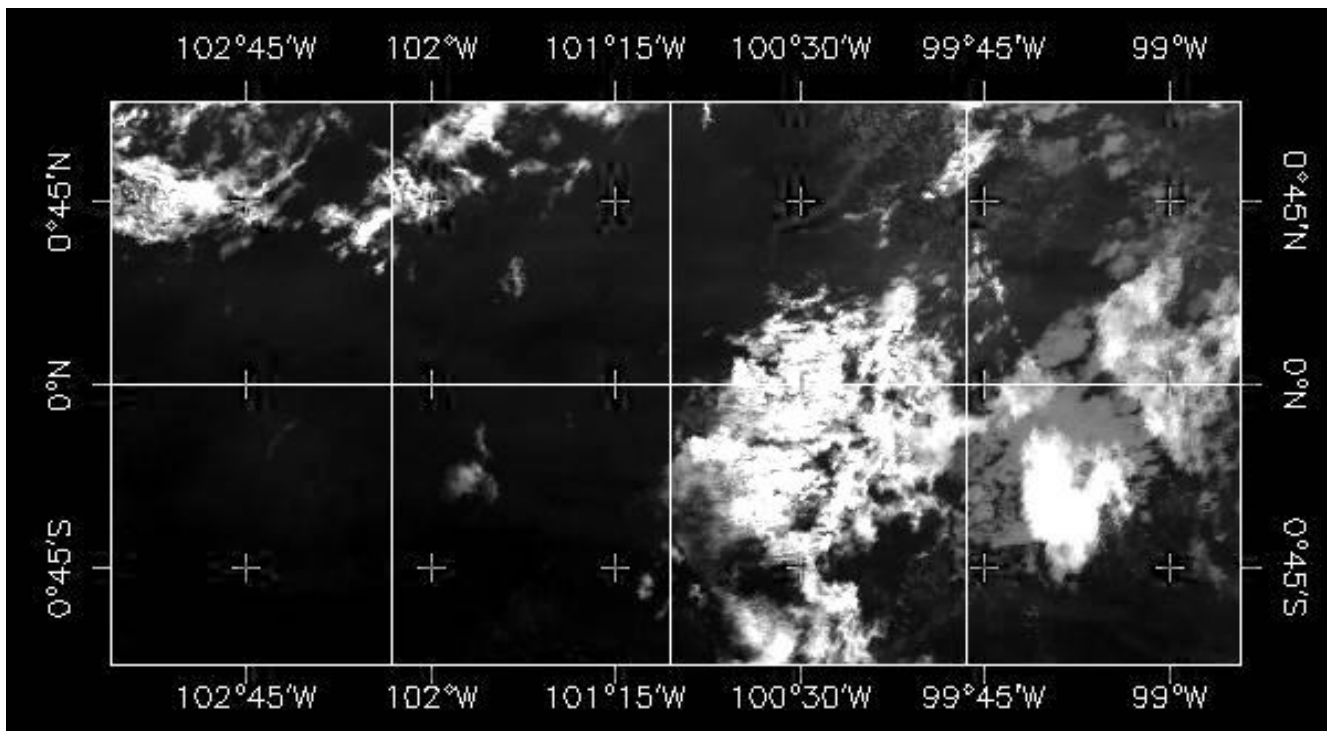

Figure 5 


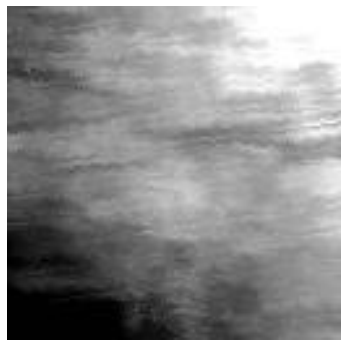

$\mathrm{a}$

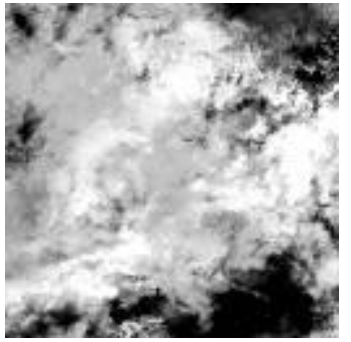

d

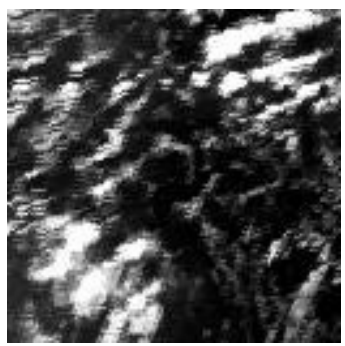

b

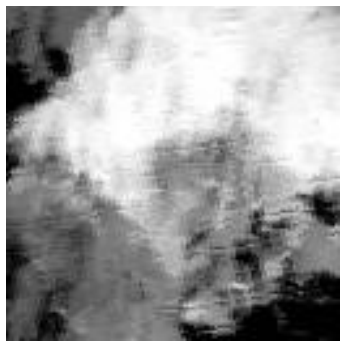

e

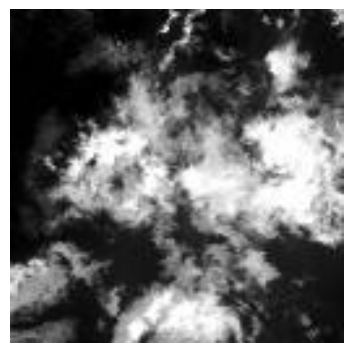

C

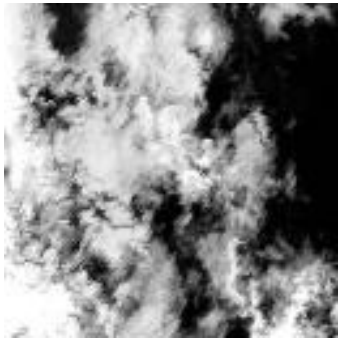

f

Figure 6 